\title{
Executive and Leadership Coaching for LGBTQ+ Populations in Corporations: Reviewing Literature to Inform Practice and Future Research
}

\author{
Vanessa G. Tennyson \\ Capitalize Your Humanity, Minneapolis, MN, USA \\ Email: vanessatennyson@outlook.com
}

How to cite this paper: Tennyson, V. G. (2021). Executive and Leadership Coaching for LGBTQ+ Populations in Corporations: Reviewing Literature to Inform Practice and Future Research. Open Journal of Leadership, 10, 364-380.

https://doi.org/10.4236/oj1.2021.104021

Received: September 15, 2021

Accepted: December 28, 2021

Published: December 31, 2021

Copyright (c) 2021 by author(s) and Scientific Research Publishing Inc. This work is licensed under the Creative Commons Attribution International License (CC BY 4.0)

http://creativecommons.org/licenses/by/4.0/

\begin{abstract}
This study reviews the existing inclusion of LGBTQ+ populations in corporate executive coaching programs and makes the case for integrating LGBTQ+ individuals into corporate executive coaching programs. This research concentrates on the unique perspective of the LGBTQ+ population and the impact executive coaching can have on behavioral authenticity leading to enhanced performance and diversity of thought. Methodology incorporated literature reviews and includes interviews of self-identified LGBTQ+ leaders. Major findings include identification of common corporate practices and the benefits of executive and leadership coaching for LGBTQ+ leadership development. Additional findings include an understanding of development opportunities for LGBTQ+ leaders, and how executive and leadership coaching provides superior results for both LGBTQ+ leaders and their corporations.
\end{abstract}

\section{Keywords}

Executive Coaching, LGBT Leadership, Leveraging Diversity

\section{Introduction}

The term LGBTQ+ is used in this paper, defined as an all-inclusive group, listed by sexual preference with the initials L-Lesbian; G-Gay; B-Bisexual; TTransgender; Q-Queer or Questioning; +-All Other Sexual Minorities. The purpose of this paper is to explore barriers to LGBTQ+ leadership development. Executive coaching has been embraced as an effective tool for C-Suite, executive and management staff, and yet, there is a considerable lack of engagement in this process for diverse populations. The diversity \& inclusion initiatives corpora- 
tions have begun, could secure meaningful validation by exercising the wholehuman approach to development through executive coaching for these diverse individuals. By making a commitment to executive and leadership coaching for diverse populations, the corporation can benefit from a positive employee experience, both within and outside of the corporation, leading to a desire from diverse employment candidates to work for the company. Fully incorporated inclusion initiatives create an environment where employees feel valued, and aid in the overall opportunity for enhanced profitability, by the value employees bring. When the benefits of executive coaching are extended to diverse populations, they can be fully engaged in the opportunity for development of self, through the skill of executive coaches who focus on client insight through explorative questions.

\section{Review of Selected Literature}

\subsection{Protocol}

Using Google Scholar, the initial literature review was explored with the following key words: LGBTQ+ coaching, LGBTQ+ leadership and LGBTQ+ executive coaching. During the initial search, an article from Sage Journals titled LGBT Career Development was discovered, so the key word search was expanded using LGBT+ coaching, LGBT+ leadership and LGBT+ executive coaching.

\subsection{Definitions}

Semantics are important and thoughts regarding meaning can be quite dynamic. The following terms or phrases are defined for contextual awareness in a manner that hopefully normalizes the language used.

Career

1) "a profession for which one trains, and which is undertaken as a permanent calling"

2) "a field for or pursuit of consecutive progressive achievement especially in public, professional or business life” (Merriam-Webster, 2019)

Career Development

"The total constellation of psychological, sociological, physical, economic, and chance factors that combine to influence the nature and significance of work in the total lifespan of any given individual" (Australian Centre for Career Education, 2019)

"A person's creation of a career pattern, decision-making style, integration of life-role self-concepts"

Cisgender

"Of, relating to, or being a person, whose gender identity corresponds with the sex the person had or was identified as having at birth (cis Latin "on this side of")" (Merriam-Webster, 2021) 
Coming Out or Coming Out of the Closet

"An awakening as to who you really are in terms of sexual orientation and attraction, which usually does not fit mainstream heterosexism, and deciding to tell certain people in your life that you are lesbian, gay, bisexual, transgender, etc." (Urban Dictionary, n.d.)

Corporate Social Responsibility (CSR)

"...the obligation of businessmen to pursue those policies, to make those decisions, or to follow those lines of actions which are desirable in terms of the objectives and values of society" (Bowen, 1953)

Disposable Personal Income (DPI)

"The amount that U.S. residents have left to spend or save after paying taxes." (Personal Income - Personal Taxes) (Bureau of Economic Analysis, n.d.)

Having a Voice and conversely Voicelessness

"To have an active and participatory role in making or influencing a decision about something" (The Free Dictionary, 2019)

Implicit Bias (also Unconscious or Unintentional Bias)

"Prejudice or unsupported judgements in favor of or against one thing, person, or group as compared to another, in a way that is usually considered unfair" (Vanderbilt University, n.d.)

Pink Dollar or Pink Money

"The collective spending or purchasing power of the homosexual community." (The Free Dictionary, 2018)

Guiding Principles

Earn the Right to Advance "Help clients move from the general to the specific; Help clients connect potential options to core organizational and personal values; Help clients make explicit progress"

Build Commitment through Involvement "Talk less; listen more; Realize that opposition and resistance is a natural part of the learning and change process; Involve the client at every phase of the coaching process" (Columbia Coaching Program, n.d.)

Core Coaching Competencies and Competency Clusters

Co-Create the Relationship:

Leveraging Diversity "Seeks to understand world view, Helps client see different perspectives, Devise approaches to identify relevant diversity and cultural factors, Applies diverse insights, Tracks impact of diversity on outcomes" 
Make Meaning with Others:

Listening "Works to capture meaning"

Testing Assumptions "Identifies client perceptions, Helps client discover for themselves, Explores blind spots"

Helping Others Succeed:

Reframing “Transforms perceptions, Encourages clients to cross boundaries"

Business Acumen "Establish credibility, Influence by linking behavior to knowledge" (Columbia Coaching Program, n.d.)

\section{Literature Review to Inform Practice and Future Research}

As I started my literature review, I expected that the topic would be obscure due to its narrow scope. What I did not expect was external validation that executive and leadership coaching for LGBTQ+ populations in corporations would be considered valuable, and yet, there it was in a program announcement from the Stanford Graduate School of Business, for their LGBTQ Executive Leadership Program. The program began in July of 2016, advertised as the only program of its kind to be offered by a leading business school, that addresses the gap in LGBTQ+ leadership in the C-Suite. The program focuses on five main practices, including learning how your LGBTQ identity influences and strengthens your personal leadership style, and assess and refine your interpersonal skills to become an authentic leader. Since Stanford is a well-regarded academic institution, you'd most likely entertain the notion that the advent of this program would also increase interest in research surrounding this topic. Unfortunately, that is not the case. I have found very little research on executive and leadership coaching for LGBTQ+ populations. Breaking it down further, there seems to be no research at all on the transgender population.

Focusing on the acronym LGBT as the main source for research, there are some interesting statistics available to refine and clarify this population. According to the UCLA School of Law, Williams Institute, as of March 2019, there are over 11.25 million adult Americans who self-identify as gay, lesbian, bisexual, or transgender, representing $4.5 \%$ of the American population, and $6.5 \%$ of the currently employed workforce (Bowen, 1953). In terms of economic impact, the disposable personal income (DPI) within the LGBTQ+ community, also known as the pink dollar, was recently calculated to be $\$ 917$ billion (Witeck Communications, 2015).

“The LGBTQ+ community doesn't take anything at face value and holds a high standard of scrutiny for any attempt to attract its business." (Petrock, 2021) Brand Loyalty contributes to 4 key factors of success. 1) Increased Customer Lifetime Value (CLV): When your customers buy from you again, their CLV increases. 2) Higher-Order Values: Loyal consumers are likely to purchase more items from you. 3) Lower Cost of Acquiring a Customer (CAC): The cost of ac- 
quiring customers is lowered as loyal customers spread the word of your brand via word of mouth. 4) Improved Profitability: Without brand loyalty, CAC stays high, while CLV and order values remain low (Mayfield, 2021). Given the size and earning power of this workforce, any corporation would find an executive and leadership coaching program for LGBTQ+ individuals to be highly beneficial, leading to increased morale through self-awareness and authenticity, brand loyalty, and increased profitability as a result.

The LGBTQ+ population today is generally relying on self-development without the benefit of organized and sponsored leadership development programs. Although this percentage of the population may not seem like much, it is my contention that it would be inappropriate, ineffective, and directly opposed to most mission and vision statements, for companies to turn a blind eye on $6.5 \%$ of their population. Many corporations now have a diversity and inclusion officer charged with increasing and engaging their minority populations. As a result of this universally accepted need for diversity engagement and inclusion, the natural extension is to enhance executive and leadership programs to engage this population. $80 \%$ of mid and senior level management, and $87 \%$ of high potential employees are offered leadership coaching. The rationale corporations use is quite clear, with performance management, communication skills, relationship building and team effectiveness, all scoring above $60 \%$ in reasons for offering coaching (International Coaching Federation, 2021).

Even though corporations currently embrace executive and leadership coaching as a valued process, cost always seems to come up as a deterrent. The Stanford LGBTQ Executive Leadership Program has now been in existence for five years, and as such could be classified as an operational success. In breaking down the cost of this program, tuition is $\$ 13,000$ including accommodations, meals and refreshments for 5 days. By any measure, this is a small cost for the corporation to create comfort and confidence from the knowledge that you are not alone in your corporate journey as a LGBTQ+ identified individual. If however, the individual is bearing the brunt of the cost for this program, it would seem to be prohibitive.

Stanford advertises that their program helps LGBTQ+ executives understand how their LGBTQ+ identity influences and strengthens their personal leadership style and refines interpersonal skills, to become an authentic leader. Corporate executive and leadership coaching initiatives for LGBTQ+ populations should draw inspiration from and be encouraged by the success of the Stanford program. Executive and leadership coaching within the LGBTQ+ population is not only good business, with a measurable return on investment (Phillips et al., 2012), it is an expansion of the ability of corporations to reach all their diverse populations (Johnson, 2015).

Unfortunately, the isolation of diverse populations has been a societal norm. (Hollis \& McCalla, 2013) That isolation need not exist if we push forward the notion that women, people of color, people with disabilities, and other minorities, will benefit from the idea that executive and leadership coaching belongs to 
the entirety of populations. When embracing all populations, corporations expand their ability to capitalize on different views of the same situation. In management, exploring differences is a mandate, since discovering what sets them apart from their competition is a necessary exercise for survival. Using that same directive, executive and leadership coaching within diverse, and in this case LGBTQ+ populations, expands their vision in exploring differences that set them apart, reinforcing the Diversity Equity and Inclusion initiatives (DEI) that have become exceedingly imperative within corporations. The LGBTQ+ population, like any minority population, has had to deal with workplace related issues that are not common to the white male population that currently dominates the executive and leadership roles within corporations. I believe that the statistics stated above, combined with the unique workplace related issues associated with being LGBTQ+, makes a compelling case for expansion of existing executive and leadership coaching programs to be intentionally more inclusive of all minorities, as part of their DEI initiatives (Croteau, 1996). Making the case from a statistical view for LGBTQ+ executive and leadership coaching is certainly important; however, statistics do not describe the whole-human experience that executive and leadership coaching can provide (Ghama \& Spence, 2019). In my coaching practice, I emphasize that coaching is about people, regarding behavioral authenticity, and for performance, with the desired end result of a better understanding of who we are when we engage our authentic selves. Applying this philosophy to the LGBTQ+ population takes on new meaning, due to widespread discrimination of this group (as described by Smith et al., 2013; Stoll, 2009; Taylor, 1997; Tilcsik, 2011; Williamson, 1993). In my lived experience, being aware of individual diversity and embracing all it has to offer should be intuitive, and yet all too often, diversity is subject to ridicule, derision and hate. It's not hard to see where intolerance manifests. As humans, we generally don't like things that are unfamiliar or different. For a variety of reasons, that unfamiliarity turns to fear, manages to take hold and then turns to hate. Hate then is the lasting impact of intolerance. However, when corporations, acting in their own self-interest, engage diverse populations through executive and leadership coaching, they begin to view society as being necessarily diverse by design, and therefore regard inclusivity as an extension of that diversity. In this paradigm, we accept that being different should be honored and celebrated, not feared or scorned. When we see the world through the lens of diverse populations, other perspectives are experienced, possibly embraced, and allow for the opportunity of engagement in change. Imagine the transformation that can occur when a person that has been subject to disdain and derision their entire life, explores what true value they have as individual contributors to commerce and society by being their authentic self, and not what someone else expects them to be.

In every business, there are decisions that define their representation in both commerce and society. In reviewing the statistical evidence, the business case, and the social paradigm, executive and leadership coaching for the LGBTQ+ population should be a very simple decision. The time has come to expand the 
widely accepted and practiced process of executive and leadership coaching, into diverse populations. My coaching process starts with the inviolate principle of encouraging the development of a collaborative relationship in which both parties agree to open and honest dialogue without fear of judgement (Rogers, 1961). An understanding that the coach does not have the answers, only the client has the answers, and it is the coach's mandate to assist the client in exploring their intellect and emotions so that they may engage their true self. Navigating the journey to behavioral authenticity is neither straightforward nor easy. It requires collaborative work. The coach must allow for the client to explore spaces that may be uncomfortable and sometimes emotionally difficult. However, given the right coaching relationship, the client will have the opportunity to discover and then engage their authentic self, while co-creating the relationship, which allows for the exploration of shared knowledge and experience.

Exploring executive and leadership coaching for the LGBTQ+ population is fraught with emotion. Unlike the cisgender population, the LGBTQ+ population has had to struggle with their identity throughout the course of their lives. This is compounded by the fact that unlike gender and race differences which are for the most part visible, sexual orientation and gender identity are not necessarily visible, and unconscious bias may actually cause confusion and stress with mistaken sexual minority identity (McCormick, 2015). For example, an athletic woman who likes short hair and comfortable attire, may be mistaken for being lesbian, simply due to the unconscious bias association. In my own case, transitioning as a transgender woman, the most frequent comment was "but you were a man's man", requiring an explanation defending my decision as appropriate. This emotional morass has left an indelible mark on almost all persons within this population. Even in the most accepting circumstances, coming out is always a soul-searching moment filled with fear and anxiety, formulated from years of societal pressure to conform. Heterosexism is common, requiring a sense of vigilance by the LGBTQ+ person as they manage their career. In 2018, the Human Rights Campaign released the results of a survey of employees across the United States, revealing the persistent daily challenges to LGBTQ+ identified populations. $46 \%$ of LGBTQ+ workers say they are in the closet, $20 \%$ report they have been told they should dress in a more feminine or masculine way, and 31\% represent they are unhappy or depressed at work. Additionally, a LGBTQ+ person may in fact have to decide whether to come out on multiple occasions. During career development cycles, changes in employment are common. An external change to a different company, an internal change to a department in a different facility or geographical location, or even an international assignment within a multi-national corporation. All these changes may require a choice to be made on whether to come out, as a matter of personal authenticity, or to stay in the closet, to protect career development opportunities. Coming out takes on many forms. A picture on a desk of your partner/spouse and children or bringing your partner/spouse to an event, both describe situations that the LGBTQ+ 
population must navigate with careful consideration, that other populations take for granted. After coming out, lack of visibility, voice-lessness and dealing with unconscious bias, are constants in the life of a LGBTQ+ employee. The emotional toll of navigating these daily rigors that have nothing to do with job performance, can be devastating to career development, as well as physical and mental health and well-being (as described by Alderson, 2003; Badgett et al., 2013; Gedro et al., 2004; Gedro, 2009).

The LGBTQ+ population also experiences widespread discrimination in the workplace. LGBTQ+ discrimination takes on many forms and can be quite pervasive, and despite a paucity of research on the subject, 20 states have enacted laws that prohibit discrimination based on sexual orientation and gender identity (MAP, 2018). There are no federal laws that seek to prevent discrimination against the LGBTQ+ population, and in August 2019, the United States Department of Justice on behalf of the Trump administration filed an amicus brief with the United States Supreme Court arguing that Title VII of the Civil Rights Act of 1964, does not protect gay and transgender workers against employment discrimination (United States Supreme Court, 2018).

To be certain, having an identity as a sexual minority exposes a LGBTQ+ person to hire, fire, raise and promotion discrimination in the workplace, as well as multiple forms of harassment, violence, derision, and disdain inside and outside of the workplace. Individually, the LGBTQ+ population faces additional types of discrimination. A LGBTQ+ individual who identifies as lesbian also must deal with sexism. A LGBTQ+ individual who identifies as transgender must deal with what I have termed facilities discrimination and expression discrimination. Facilities discrimination involves having to choose which bathroom, locker room, or changing facility to use. Expression discrimination involves having to choose what clothing to wear based on societal expectations. Each of these forms of discrimination have developed due to having a chosen rather than assigned gender identity. These added layers of discrimination amplify the angst of LGBTQ+ individuals in simply trying to negotiate their day-to-day needs.

Behavioral science and neuroscience research posit other factors that help explain difficulties for the corporate LGBTQ+ population. Neuroscience informs us that the brain creates neural pathways to assist in ever-quickening processing of behaviors. In creating these neural pathways, the brain develops a traffic-jam-free highway of thought, adding more neurons available for the process through frequently repeated behaviors. If those behaviors are to be changed, the brain must then create a new highway altogether. In the LGBTQ+ population, there are behaviors that are created as a matter of self-preservation based on external demands that are mis-aligned with the internal process of acceptance (McFadden \& Crowley-Henry, 2017). It therefore makes sense that a LGBTQ+ employee-cum-manager would struggle with the behavioral comfort required to be an effective leader, likely having never experienced a role model to influence accepted behavior. In his breakthrough book, Emotional Intelligence: Why It Can 
Matter More Than IQ (Goleman, 2005) describes the 5 skills of emotional intelligence. Self-awareness, Self-regulation, Motivation, Empathy and Social skills, have been widely accepted as behaviors that a successful leader must develop in order to lead effectively. The executive and leadership coach utilizes emotional intelligence to help guide the client in recognizing and developing their own emotional intelligence as a leader.

The multiplicity of issues that identifying as LGBTQ+ brings into the public domain can be daunting for the corporation. The recently named CEO of Land O'Lakes, Beth Ford, identifies as a lesbian (Fortune, 2018). How should Land O'Lakes decide to announce their decision? Is Beth Ford a female CEO, is she a lesbian CEO, is she both? Or, is she simply the CEO of a Fortune 500 company? In addition to Beth Ford, there are 2 additional openly LGBTQ+ individuals who are CEOs of Fortune 500 companies. Tim Cook at Apple, Jim Fitterling at Dow Chemical, and a listing of LGBTQ+ executives can be found in the report, Top 100 LGBT+ Executives, as published by the diversity charity INvolve, identifying individuals who work within 3 levels of chief executive at large companies. Why is this type of public recognition important? Why is this type of public recognition necessary? Because it lends credence and validation to the idea that identifying as an individual within the LGBTQ+ community does not have to be a secret for individuals to thrive in a corporate environment. In a recent interview, Beth Ford said "I made a decision long ago to live an authentic life, and if my being named CEO helps others do the same, that's a wonderful moment. This is not a story of someone getting into the higher echelons of leadership and then coming out, this is someone who is walking into this role with her full self." (CNN, 2018). In another interview she said "I think it must be really hard if you feel like you're in a culture where you can't be who you are. Work is hard enough, and then when you have to feel as though you can't be who you are, that's got to be incredibly difficult.". This recognition is an important step. While it is still the exception rather than the norm, and for the over 10 million LGBTQ+ employees in the United States, does little to guide them along their career development paths, it does identify LGBTQ+ individuals who have risen to the executive level, and can help identify the starting point from which executive and leadership coaching for the LGBTQ+ population may begin. In today's ever tightening labor market, that could be a major advantage by tapping into a source of unmaximized talent. As Marion Wright Edelman wrote "You can't be what you can't see", so visibility that an employer values diversity throughout, has a direct impact on recruitment of top talent (Malterud \& Bjorkman, 2016).

As Beth Ford noted "... when you have to feel as though you can't be who you are, that's got to be incredibly difficult.", she was speaking about the daily emotional discipline it takes to perform any job, while having to manage your personal identity, and the strain on your performance as a result. What does that mean quantifiably to corporations? In a study published in 2015 by Out Now LGBT 2030, 11 countries surveyed as part of this groundbreaking research to determine the effects of "being in the closet" versus "being out of the closet" on 
productivity. In the United States, a full $30 \%$ increase in productivity was measured by not having to manage personal identity. In US dollars, that would create an additional $\$ 1.7$ to $\$ 12.8$ million annually within corporations of 100,000 employees. "...on a national basis is measurable in the hundreds of millions or even low billions of dollars in expenditure saved by not having to replace workers who leave because they cannot 'come out' as LGBT at work."

Corporate television advertising recently gave a compelling example of the complexity of issues surrounding LGBTQ+ identity in the public domain. In December 2019, Hallmark channel removed an advertisement for the wedding planning site Zola, which showed a lesbian couple kissing, after online petitions from two conservative groups objected to the commercial. Less than a week later, the commercial was reinstated in its original form, after an online firestorm from LGBT-rights groups. "This story really shows us that brands have to move quickly today when it comes to making decisions" said Tim Calkins, clinical professor of marketing at Northwestern University's Kellogg School of Management.

Corporate programs that embrace the development needs of the LGBTQ+ population are rare, if in existence at all, and executive and leadership coaching is uniquely positioned to assist in the development of LGBTQ+ individuals who may then create, refine, and implement policies and systems that benefit the entirety of corporate minority populations. A practiced and skilled executive and leadership coach will help the LGBTQ+ individual embrace their authentic self, and if we cite Beth Ford's experience, success need not come at a cost to living an authentic life (Nourafshan, 2018). Navigating the obstacles unique to the LGBTQ+ individual, while managing successful career development does not have to be random. Effective executive and leadership coaching guides the experience by drawing on lived experience of self and others, thereby allowing for expanded perspective. These additional layers add depth and can be used to enhance and expand the capability and understanding of the LGBTQ+ population in leadership and executive positions (as described by Pia Garcia Johnson, \& Otto 2019; Rocco et al., 2009; Llouren \& Parini, 2017). Given the highly competitive nature of business in today's economy, providing the corporation and its' key individuals with the opportunity to see through the lens of a diverse population, can only serve to enhance the ability of both to better serve its chosen purpose.

Based on pioneering work of Howard Bowen and his model of Corporate Social Responsibility (CSR), there would seem to be definitive advantages for the expansion of CSR into LGBTQ+-supportive policies, including executive and leadership coaching initiatives for LGBTQ+ populations. In their first of a kind study directly testing the relationship between CSR and LGBT-supportive policies, it was concluded that 1) LGBT-supportive corporate policies are positively associated with firm value, productivity and profitability, and 2) the positive associations increase with engagement in R\&D activities (Pichler et al., 2018). 


\section{Summary of Major Findings}

\subsection{Enhanced Firm Performance}

Diversity at the organizational level and organizational support for diversity in terms of policies and practices (e.g., executive and leadership coaching for LGBTQ+ populations) are related to enhanced firm performance (Kossek \& Pichler, 2009).

\subsection{Market Penetration}

The DPI of the pink dollar has been recently estimated at $\$ 917$ billion (Witeck Communications, 2015) and the LGBTQ+ population is distinct in that they are brand loyal, preferring to buy products from companies with LGBTQ+ supportive corporate policies and practices (Petrock, 2021). From 1994 to 2005, the number of Fortune 500 companies that have LGBTQ+-targeted advertising campaigns, has grown from 19 to 175 . When corporations spend money on a particular market segment, they seek to maximize profit through those dollars.

\subsection{Talent Recruitment, Retention \& Performance Enhancement}

Creating inclusive work environments through the adoption of LGBTQ+ supportive policies and practices, helps establish companies as "employers of choice" for all employees, not just LGBTQ+ employees (Cordes, 2012). Better employee recruitment and lower employee turnover (Metcalf \& Rolfe, 2011), along with a less-stressful work environment that allows employees to be open and out of the closet (Ragins et al., 2007), are key indicators of performance enhancement. Corporate cultures where diversity and openness thrive are more likely to attract top talent, especially young, creative, and entrepreneurial candidates (McPherson).

\section{Application and Implication for Coaching Practice}

The absence of any substantive executive and leadership coaching for LGBTQ+ populations in corporations, allows for the expansion of the craft into other audiences within corporations. LGBTQ+ populations have been isolated, ignored, discriminated against, derided, and demeaned for generations. Consumer demand for increased diversity in corporate policies supports consumer product selection, effectively driving the need for corporations to promote and embrace LGBTQ+ leadership along with all other minority populations, making corporations diverse by design. Since corporations have previously identified executive and leadership coaching as an effective process to enhance and expand the capabilities of their executives and leadership ranks, the expansion to minority leadership is a natural evolution. What makes LGBTQ+ populations unique, also creates new opportunities for executive and leadership coaches belonging to LGBTQ+ populations, to use their skills, perspective, and experiences, to elevate the behavioral authenticity of these leaders and executives, by helping them dis- 
cover the strength within their identity, even though the journey will take courage and resilience.

\section{Columbia Coaching Certification Program (3CP) Guidelines and Competencies}

Columbia University, through the research and teachings of Dr. Terrence E. Maltbia, Associate Professor and Faculty Director, Columbia Coaching Programs, has given us a direct link to effective executive and leadership coaching for diverse populations. The Guiding Principles, describe 4 areas of focus, and the Core Coaching Competencies, describe 9 clusters in 3 competencies, that have direct application to executive and leadership coaching of LGBTQ+ populations.

Within the guiding principles foundation, those identified as Building Commitment through Involvement and Earning the Right to Advance, are paramount in my practice for coaching the LGBTQ+ leader or executive. In applying these principles, I want to create an environment embracing a primary inviolate tenet of encouraging the development of a collaborative relationship, in which both parties agree to open and honest dialogue without fear of judgement. The coaching process involved, is grounded in the guiding principles of building commitment through involvement and earning the right to advance. Asking powerful questions toward client insights, helping the client overcome any resistance in the learning process, and helping them identify their own solutions builds commitment. Helping clients connect to core organizational and personal values, linking those values to goals, needs or wants, and helping clients make explicit progress is earning the right to advance. All of this is necessary to create an environment where open and honest dialogue can occur without judgement. Having achieved the primary tenet through the guiding principles of building commitment through involvement and earning the right to advance, the coachclient relationship expands naturally, and flows in a manner that is most beneficial to the client.

Within the core coaching competencies foundation, and the 3 competency clusters of Co-Create the Relationship, Making Meaning with Others, and Helping Others Succeed, the seeds of coaching the LGBTQ+ individual are planted and guide the coaching practice. Dr. Maltbia emphasizes that Leveraging Diversity is one of the key precepts in co-creating the relationship for effective executive and leadership coaching. As one of the 9 basic elements of the core coaching competencies, leveraging diversity is used extensively in providing the LGBTQ+ population within corporations, the benefits of executive and leadership coaching. When coach and client are aligned in the primary tenet of open and honest dialogue without judgement, the exploration of diversity through the worldview of the client, while allowing for differences in perspectives that create diversity of insight, opens up all the possibilities of what I call behavioral authenticity. Leveraging diversity helps creates the opportunity to advance into the competency 
cluster making meaning with others, through questioning, listening and testing assumptions. The application of these competencies in the executive and leadership coaching process can then proceed to the final phase of helping others succeed. Through reframing, by developing new approaches and related behaviors that may help transform initial perceptions, and the application of business acumen from lived experience, the executive and leadership coach can guide LGBTQ+ individuals into a new dimension of living with behavioral authenticity.

\section{The Triad of Discovery}

When applying these techniques, the LGBTQ+ client can experience what I call The Triad of Discovery.

The Triad of Discovery@

\section{Behavioral Authenticity}

o Ludgement is limiting, remember to embrace curiosity

o Open yourself up to diversity of thought and cultural awareness

o Unlock your behavioral authenticity with intention and purpose

o Reflect on your values, recognize your own bias or cultural impediments

o Nurture yourself with kindness, empathy, and patience for the process

o Explore with courage and confidence, do not let fear intervene

o Your path is unique, no two journeys are alike

\section{Final Conclusions}

With a trained, practiced, certified and skilled executive and leadership coach, the LGBTQ+ client will discover their own solutions to wants, needs, and goals. The executive and leadership coach, and more narrowly, the LGBTQ+ executive and leadership coach, act as a guide in the exploration of client intellect and emotions, encouraging the development of emotional intelligence, and through the lens of their individual perspective and experiences, will help the client en- 
gage their true self. It is time for corporations to embrace the diversity of thought and experience that are unique to LGBTQ+ and minority populations. With the help of executive and leadership coaching, LGBTQ+ populations can begin to engage in the celebration of behavioral authenticity as a driver of corporate guidance and governance, and that of enhancing society and commerce for generations to come.

\section{Conflicts of Interest}

The author declares no conflicts of interest regarding the publication of this paper.

\section{References}

Alderson, K. G. (2003). The Corporate Closet: Career Challenges of Gay and Lesbian Individuals. The Education Resources Information Center. https://eric.ed.gov/?id=ED481087

Australian Centre for Career Education (2019). Definition of Career Development. https://ceav.vic.edu.au/career-development/definition-of-career-development

Badgett, M. V., Lee, Durso, L. E., Mallory, C., \& Kastanis, A. (2013). The Business Impact of LGBT-Supportive Workplace Policies. The Williams Institute.

https://escholarship.org/uc/item/3vt6t9zx

Bowen, H. R. (1953). President Howard Bowen \& Corporate Social Responsibility. Grinnell College.

https://grinnell.edu/news/president-howard-bowen-corporate-social-responsibility

Bureau of Economic Analysis (n.d.).

https://www.bea.gov/data/income-saving/disposable-personal-income

CNN (2018). Land O'Lakes CEO Beth Ford, from the Cornfield to the C-Suite. CNN.com. https://www.cnn.com/2018/10/01/business/land-o-lakes-beth-ford/index.html

Columbia Coaching Program (n.d.). https://www.tc.columbia.edu/coachingcertification

Cordes, C. L. (2012). The Business Case for Offering Domestic Partner Benefits. Compensation \& Benefits Review, 44, 110-116. https://doi.org/10.1177/0886368712450984 https://journals.sagepub.com/doi/10.1177/0886368712450984?icid=int.sj-abstract.simil ar-articles.3\&

Croteau, J. M. (1996). Research on the Work Experiences of Lesbian, Gay and Bisexual People: An Integrative Review of Methodology and Findings. Journal of Vocational Behavior, 48, 195-209. https://doi.org/10.1006/jvbe.1996.0018 https://psycnet.apa.org/record/1996-00261-007

Fortune (2018). Land O'Lakes CEO: “Careers Are a Journey”. Fortune.com. https://fortune.com/2018/10/02/beth-ford-land-o-lakes

Gedro, J. A. (2009). LGBT Career Development. Advances in Developing Human Resources, 11, 54-66. https://doi.org/10.1177/1523422308328396

Gedro, J. A., Cervero, R. M., \& Johnson-Bailey, J. (2004). How Lesbians Learn to Negotiate the Heterosexism of Corporate America. Human Resource Development International, 7, 181-195. https://doi.org/10.1080/1367886042000243790

Ghama, I., \& Spence, G. B. (2019). “Come Out, Come Out, Whoever You Are!” Client Perceptions of Working Alliance Following Imagined Sexual Identity Disclosure in Coaching. Coaching: An International Journal of Theory, Research and Practice, 13, 146-162. https://doi.org/10.1080/17521882.2019.1656657 
Goleman, D. (2005). Emotional Intelligence Why It Can Matter More than IQ. https://www.amazon.com/Emotional-Intelligence-Matter-More-Than/dp/055338371X/

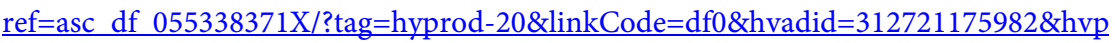
os $=\&$ hvnetw $=\mathrm{g} \&$ hvrand $=1989340558722471122$ \&hvpone $=\&$ hvptwo $=\&$ hvqmt $=\&$ hvdev $=\mathrm{c} \& \mathrm{hvdvcmdl}=\&$ hvlocint $=\&$ hvlocphy $=9019669$ \& hvtargid $=$ pla- $395617940859 \& \mathrm{psc}=1$

Hollis, L. P., \& McCalla, S. A. (2013). Bullied Back in the Closet: Disengagement of LGBT Employees Facing Workplace Bullying. Journal of Psychological Issues in Organizational Culture, 4, 6-16. https://doi.org/10.1002/jpoc.21109

International Coaching Federation (2021). 2020 ICF Global Coaching Study Executive Summary.

https://coachfederation.org/app/uploads/2020/09/FINAL ICF GCS2020 ExecutiveSu mmary.pdf

Johnson, I. (2015). LGBT Diversity: Show Me the Business Case, Out Now Global LGBT 2030 Study. http://OutNow.LGBT

Kossek, E. E., \& Pichler, S. (2009). EEO and the Management of Diversity. In P. Boxall, J. Purcell, \& P. M. Wright (Eds.), The Oxford Handbook of Human Resource Management. Oxford University Press.

https://www.researchgate.net/publication/282993853 EEO and the Management of Diversity

Llouren, A., \& Parini, L. (2017). How LGBT-Supportive Workplace Policies Shape the Experience of Lesbian, Gay Men, and Bisexual Employees. Sexual Research and Social Policy, 14, 289-299. https://doi.org/10.1007/s13178-016-0253-x

Malterud, K., \& Bjorkman, M. (2016). The Invisible Work of Closeting: A Qualitative Study about Strategies Used by Lesbian and Gay Persons to Conceal Their Sexual Orientation. Journal of Homosexuality, 63, 1339-1354.

https://doi.org/10.1080/00918369.2016.1157995

Mayfield, D. (2021). How to Build Brand Loyalty as an Ecommerce Brand. Automizely. https://www.automizely.com/blog/build-brand-loyalty

McCormick, H. (2015). The Real Effects of Unconscious Bias in the Workplace. http://execdev.kenan-flagler.unc.edu/blog/the-real-effects-of-unconscious-bias-in-theworkplace-0

McFadden, C., \& Crowley-Henry, M. (2017). "My People”: The Potential of LGBT Employee Networks in Reducing Stigmatization and Providing Voice. The International Journal of Human Resource Management, 29, 1056-1081. https://doi.org/10.1080/09585192.2017.1335339

Merriam-Webster (2019). Career. Merriam-Webster.com Dictionary. https://merriam-webster.com/dictionary/career

Merriam-Webster (2021). Cisgender. Merriam-Webster.com Dictionary. https://merriam-webster.com/dictionary/cisgender

Metcalf, H., \& Rolfe, H. (2011). Barriers to Employers in Developing Lesbian, Gay, Bisexual Ad Transgender-Friendly Workplaces. National Institute of Economic and Social Research.

http://citeseerx.ist.psu.edu/viewdoc/download?doi=10.1.1.231.3633\&rep=rep1\&type $=$ p df

MAP, Movement Advancement Project (2018). https://www.lgbtmap.org/equality-maps/non discrimination laws

Nourafshan, A. M. (2018). From the Closet to the Boardroom: Regulating LGBT Diversity on Corporate Boards. Albany Law Review, 81, 439-488. 
http://www.albanylawreview.org/issues/Pages/article-information.aspx?volume=81\&iss $\underline{\text { ue }=2 \text { \&page }=439}$

https://doi.org/10.1111/corg.12219

Petrock, V. (2021). LGBTQ+ Consumers Value Brand Support beyond Pride Month. eMarketer, Insider Intelligence, January 4, 2021.

https://www.emarketer.com/content/lgbtq-consumers-value-brand-support-beyond-pr ide-month

Phillips, P. P., Phillips, J. J., \& Edwards, L. A. (2012). Measuring the Success of Coaching: A Step-by-Step Guide for Measuring Impact and Calculating ROI.

https://www.amazon.com/Measuring-Success-Coaching-Step-Step/dp/1562868233

Pia Garcia Johnson, P., \& Otto, K. (2019). Better Together: A Model for Women and LGBTQ Equality in the Workplace. Frontiers in Psychology, 10, Article 272. https://doi.org/10.3389/fpsyg.2019.00272

Pichler, S., Blazovich, J. L., Cook, K. A., Huston, J. M., \& Strawser, W. R. (2018). Do LGBT-Supportive Corporate Policies Enhance Firm Performance? Human Resource Management, 57, 263-278. https://doi.org/10.1002/hrm.21831

Ragins, B. R., \& Singh, R. (2007). Making the Invisible Visible: Fear of Disclosure of Sexual Orientation at Work. Journal of Applied Psychology, 92, 1103-1118.

https://www.researchgate.net/publication/6200999 Making the Invisible Visible Fear and Disclosure of Sexual Orientation at Work

Rocco, T. S., Landorf, H., \& Delgado, A. (2009). Framing the Issue/Framing the Question: A Proposed Framework for Organizational Perspectives on Sexual Minorites. Advances in Developing Human Resources, 11, 7-23. https://doi.org/10.1177/1523422308328528

Rogers, C. R. (1961). On Becoming a Person: A Therapist's View of Psychotherapy. https://www.amazon.com/Becoming-Person-Therapists-View-Psychotherapy/dp/0395

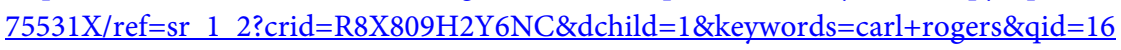
31564129\&sprefix $=$ carl\%2Caps $\% 2$ C201\&sr $=8-2$

Smith, I., Oades, L. G., \& McCarthy, G. (2013). The Australian Corporate Closet, Why It's Still So Full, a Review of the Incidence Rates for Sexual Orientation Discrimination Gender Identity Discrimination I the Workplace. Gay and Lesbian Issues and Psychology Review, 9, 51-63. http://ro.uow.edu.au/gsbpapers/373

Stoll, M. L. (2009). Boycott Basics: Moral Guidelines for Corporate Decision Making. Journal of Business Ethics, 84, 3-10. https://doi.org/10.1007/s10551-008-9684-5

Taylor III, A. (1997). My Life as a Gay Executive. Fortune Magazine, 136, 106-110. https://money.cnn.com/magazines/fortune/fortune archive/1997/09/08/230840/

The Free Dictionary (2018). Thefreedictionary.com Dictionary. https://idioms.thefreedictionary.com/the+pink+dollar

The Free Dictionary (2019). Thefreedictionary.com Dictionary. https://idioms.thefreedictionary.com/have+a+voice

Tilcsik, A. (2011). Pride and Prejudice: Employment Discrimination against Openly Gay Men in the United States. American Journal of Sociology, 117, 586-626.

https://www.jstor.org/stable/10.1086/661653

https://doi.org/10.1086/661653

United States Supreme Court (2018). Re: No. 17-1618 Bostock v. Clayton County, GA. https://www.supremecourt.gov/oral arguments/argument transcripts/2019/17-1618 b 97c.pdf

Urban Dictionary (n.d.). https://www.urbandictionary.com/define.php?term=coming\%20out 
Vanderbilt University (n.d.).

https://www.vanderbilt.edu/diversity/unconscious-bias/\#: :text=Unconscious\%20bias \%20(or\%20implicit\%20bias, that $\% 20$ is\%20usually\%20considered\%20unfair

Williamson, S. D. (1993). Is This the Right Time to Come Out? Harvard Business Review, July-August 1993, 18-27. https://hbr.org/1993/07/is-this-the-right-time-to-come-out

Witeck Communications (2015). LGBT Spending Power in US Estimated to Be Worth $\$ 917$ Billion. Gay Star News, July 202016.

https://www.gaystarnews.com/article/lgbt-spending-power-917billion-witeck 